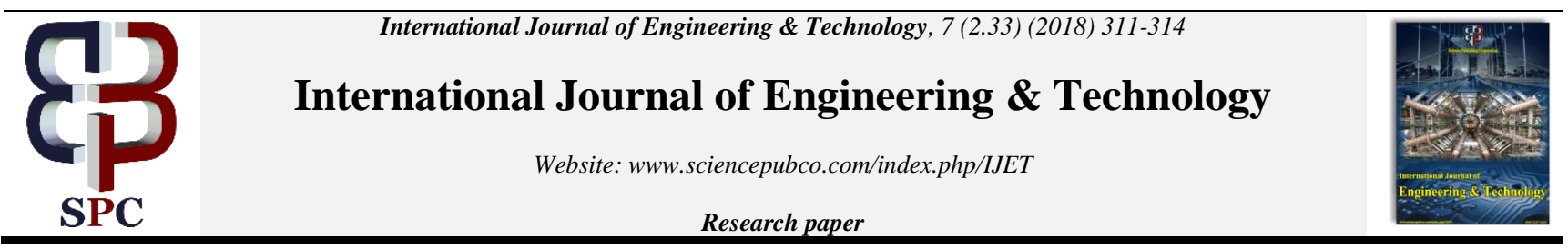

\title{
A study on flow as affected by the shape and wind speed of ventilated seat
}

\author{
Kye Kwang Choi ${ }^{1}$, Jae-Ung Cho ${ }^{2}$ * \\ ${ }^{1}$ Department of Metal Mold Design Engineering, Kongju National University, 1223-24, Cheonan Daero, Seobuk-gu, Cheonan- \\ Si Chungnam of Korea 31080 \\ ${ }^{2}$ Division of Mechanical \& Automotive Engineering, Kongju National University, 1223-24, Cheonan Daero, Seobuk-gu, Cheonan- \\ Sichungnam of Korea 31080 \\ *Corresponding author E-mail: jucho@kongju.ac.kr
}

\begin{abstract}
Background/Objectives: We studied the ventilated seats with amenities. The study has its purpose in checking the flow as affected by the shape of the ventilated seats and thereby acquiring the design factors.

Methods/Statistical analysis: In order to acquire the design factors for ventilated seats as affected by the shapes and wind speeds of the different models, we used CATIA program to design the shape, of which the flow was analyzed with ANSYS CFX program. Thus, we have acquired the design factors for ventilated seats, which data can be used to ensure higher levels of efficiency as compared to the shapes before.

Findings: For analyzing, we placed an inlet at the vent at the bottom and placed an outlet at the top by setting a boundary around it. From the setup, which had the initial wind speed at $15 \mathrm{~m} / \mathrm{s}$, the wind speed within the boundary was $29.91 \mathrm{~m} / \mathrm{s}$ for model 1 and $44.81 \mathrm{~m} / \mathrm{s}$ for model 2. At the initial wind speed of $30 \mathrm{~m} / \mathrm{s}$, we got a wind speed of $60.25 \mathrm{~m} / \mathrm{s}$ for model 1 and $88.60 \mathrm{~m} / \mathrm{s}$ for model 2 . As for the pressure and speed in the flow path as the initial wind speed of $15 \mathrm{~m} / \mathrm{s}$, we got the maximum pressure of $100.60 \mathrm{kPa}$ and the maximum speed of $29.45 \mathrm{~m} / \mathrm{s}$. For model 2, we got the maximum pressure of $102.30 \mathrm{kPa}$ and the maximum speed of $44.81 \mathrm{~m} / \mathrm{s}$. At the initial wind speed of $30 \mathrm{~m} / \mathrm{s}$, we got the maximum pressure of $102.30 \mathrm{kPa}$ and the maximum speed of $60.25 \mathrm{~m} / \mathrm{s}$ for model 1 . For model 2 , we got the maximum pressure of $105.10 \mathrm{kPa}$ and the maximum speed of $88.60 \mathrm{~m} / \mathrm{s}$.

Improvements/Applications: Through the data obtained from this analysis, the varied seat structure for additional amenities can be improved and applied with more design factors.
\end{abstract}

Keywords: Seat; Ventilation; Computational Fluid Dynamics; Finite Element Method; Speed

\section{Introduction}

With research on automobiles markedly increasing mainly in advanced countries, automobiles are so widely used these days that every home possess one or more vehicles.. For this reason, the auto industry is lately engaged in various development projects. For output, the development focuses the superchargers like turbochargers. In addition, for safety, the development of CFRP (carbon fiber reinforced plastic) can achieve the lightweight and structural stability. While such basic parts of a vehicle are being developed, the industry works no less to develop car amenities for drivers/passengers. Of them all, the study has chosen ventilated seats and has analyzed the flow as affected by its shape and wind speed [1-8].

\section{Research method and models}

In studying the shape and wind speed in a ventilated seat, we designed the shape of the ventilated seat with CATIA, for which we got two models of analysis. Figure 1 shows the shape of such a ventilated seat, with model 1 equipped with one air blower and model 2 with two air blowers.
(A) Model 1
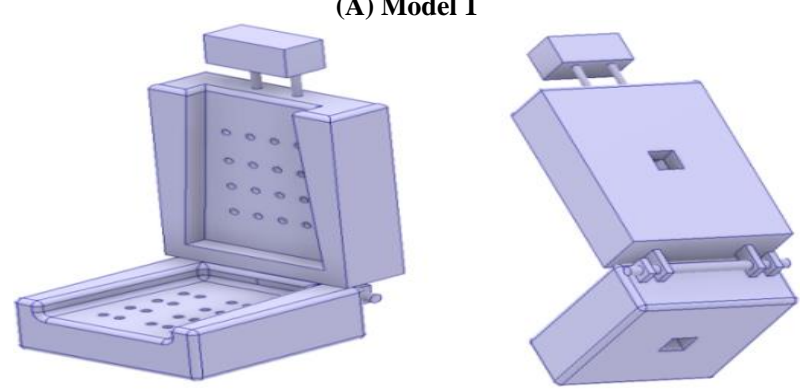

(B)Model 2
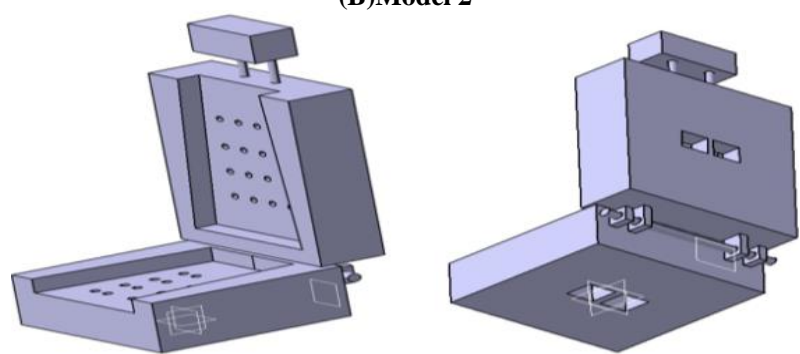

Fig. 1: Shapes of Models. 
(A)Model 1

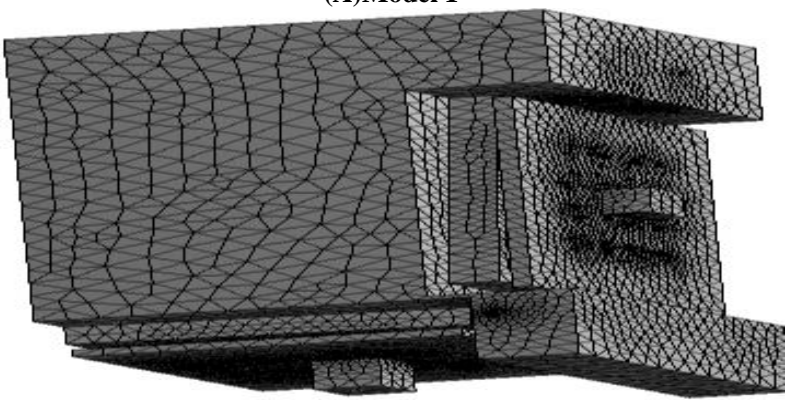

(B)Model 2

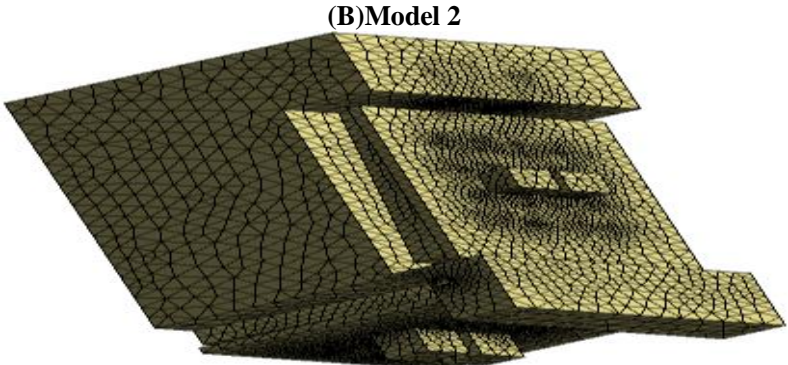

Fig. 2: Shapes of Meshes in Models.

Table 1: Nodes and Elements in Models

\begin{tabular}{lll}
\hline Model & Nodes & Elements \\
\hline Model 1 & 54868 & 272787 \\
Model 2 & 55201 & 274592 \\
\hline
\end{tabular}

Fig. 2 shows the shapes of the meshes for two models. Table 1 shows the number of nodes and elements for the models. Model 1 has 54,868 nodes and 272,787 elements, while model 2 has 55,201 nodes and 274,592 elements [9], [10].

\section{Boundary conditions}

To conduct the study on the shape and wind speed of ventilated seats, we determined the conditions of analysis as shown in Fig. 3. We put an inlet at the bottom air blower and set the speeds at $15 \mathrm{~m} / \mathrm{s}$ and $30 \mathrm{~m} / \mathrm{s}$. We set the speeds to figure out the speeds at the minimum and maximum wind speed. We put an outlet at the top portion of model. For the outlet, we set the atmospheric pressure at 1 Bar.
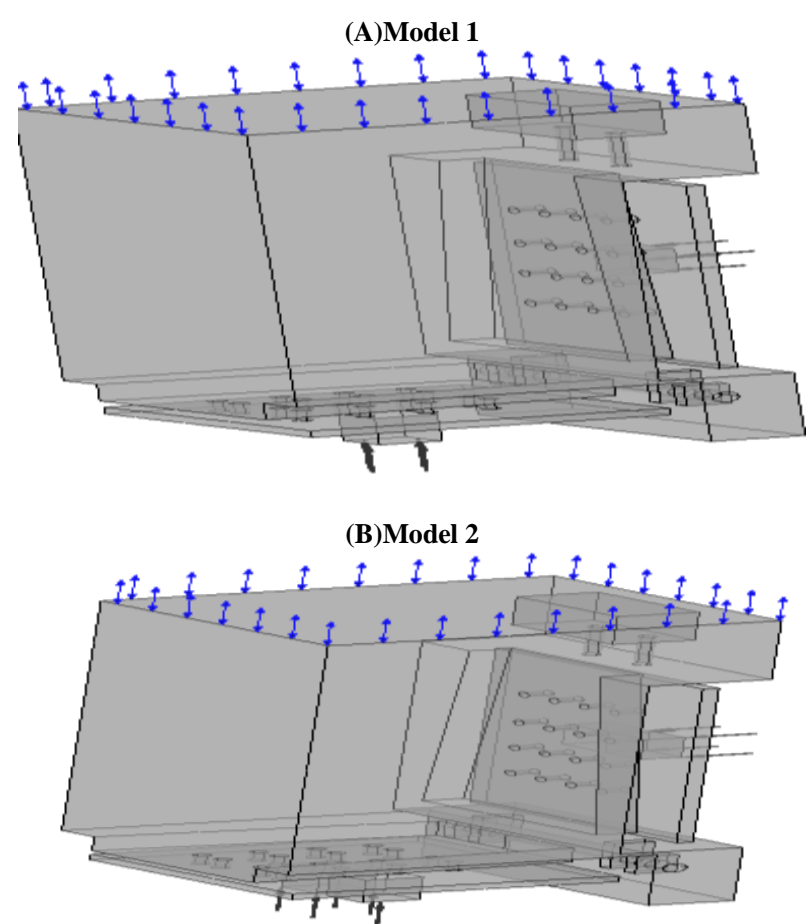

Fig. 3: Conditions of analyses of models.

\section{Simulation analysis results}

In this study, we examined the flow as affected by the shape and wind speed of ventilated seats, and have come up with the following results.

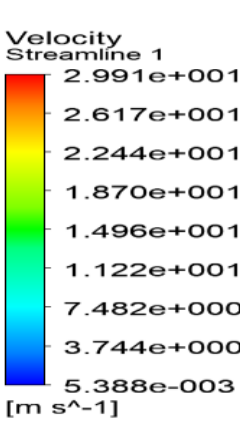

\section{(A)Model 1}

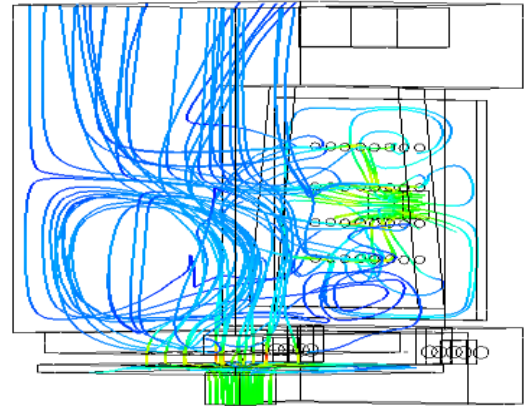

(B)Model 2
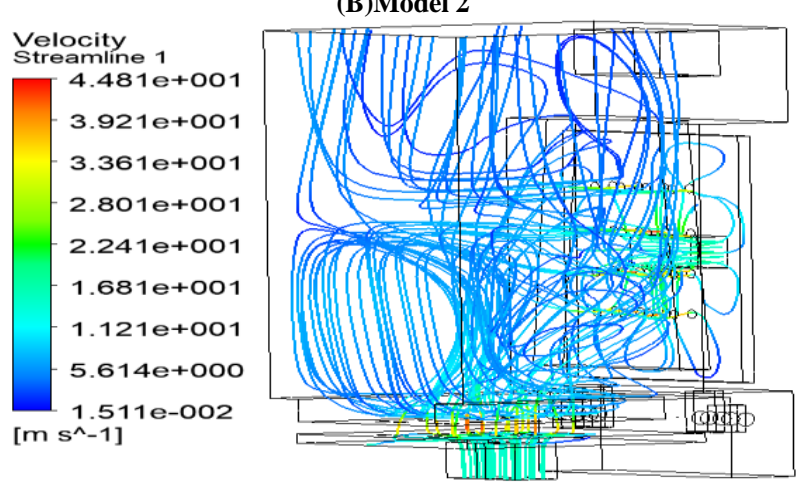

Fig. 4:.Speeds in the Entire Shapes of Models (Input Speed of 15m/s).

(A)Model 1
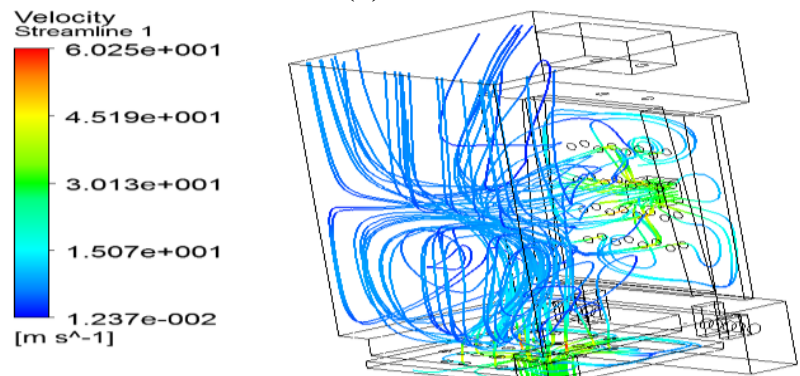

(B)Model 2
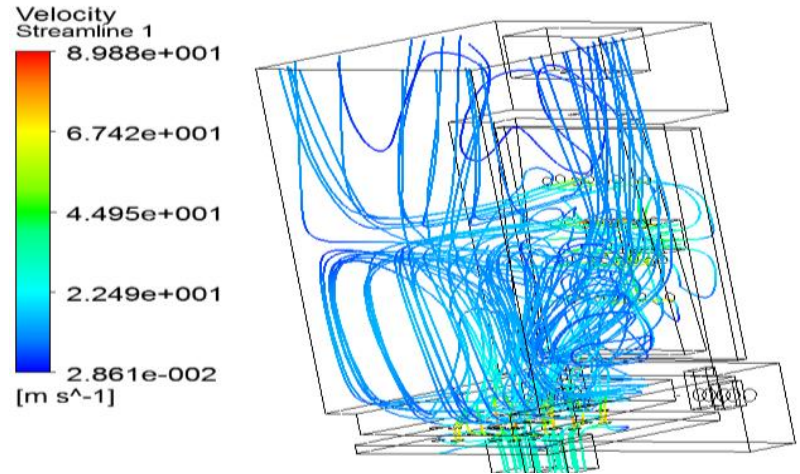

Fig. 5:.Speeds in the Entire Shapes of Models (Input Speed of 30m/s).

Fig. 4 and Fig. 5 show the speeds of the models at different wind speeds. Fig. 4 shows speeds at the wind speed of $15 \mathrm{~m} / \mathrm{s}$, showing a wind speed of $29.91 \mathrm{~m} / \mathrm{s}$ for model 1 and $44.81 \mathrm{~m} / \mathrm{s}$ for model 2 . Fig. 5 shows speeds at the wind speed of $30 \mathrm{~m} / \mathrm{s}$, showing a wind speed of $60.25 \mathrm{~m} / \mathrm{s}$ for model 1 and $89.99 \mathrm{~m} / \mathrm{s}$ for model 2 . From the results, we saw that model 2 showed the higher level of efficiency. 


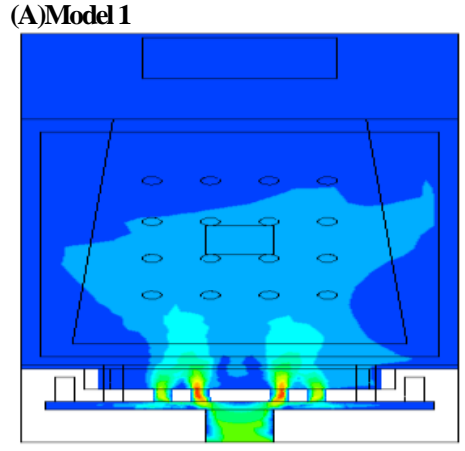

(B)Model 2
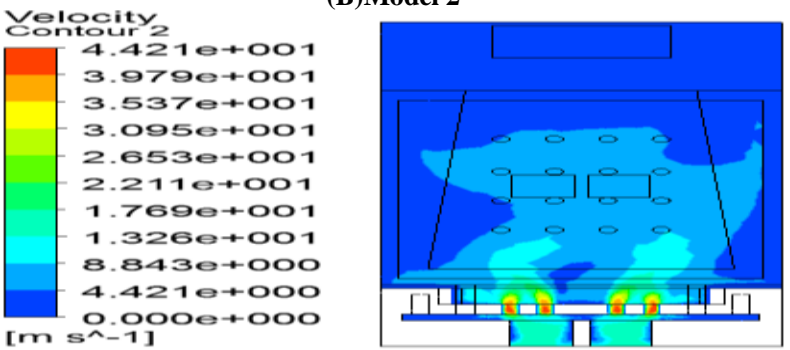

Fig. 6:.Speeds in Air Paths of Models (Input Speed Of 15m/S).

\section{(A)Model 1}
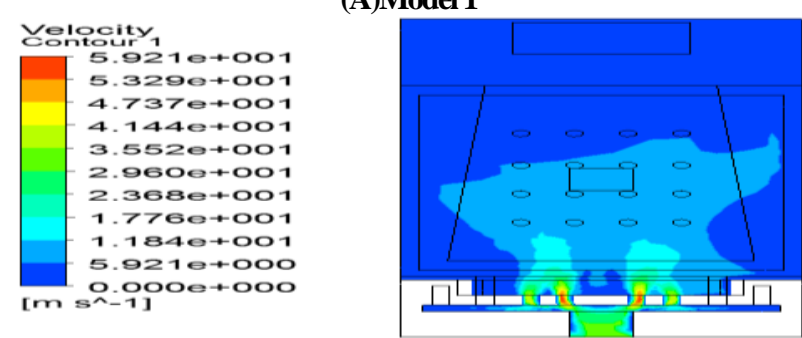

(B)Model 2
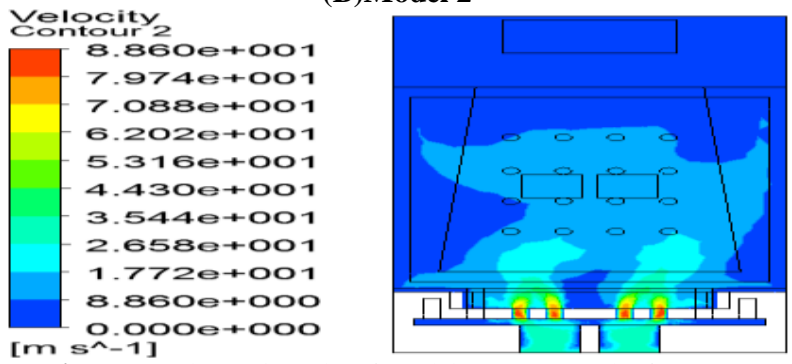

Fig. 7:.Speeds In Air Paths of Models (Input Speed Of 30m/S).

Fig. 6 and Fig. 7 show the speeds for both of the models. Fig. 6 shows the speeds at the wind speed of $15 \mathrm{~m} / \mathrm{s}$ for the inlet, marking the maximum speed of $29.45 \mathrm{~m} / \mathrm{s}$ for model 1 . Model 2 also marked a speed of $44.21 \mathrm{~m} / \mathrm{s}$. Fig. 7 shows the speeds at the wind speed of $30 \mathrm{~m} / \mathrm{s}$ at the inlet. It shows that model 1 showed a speed of $44.21 \mathrm{~m} / \mathrm{s}$ and model 2 marked the speed of $88.60 \mathrm{~m} / \mathrm{s}$,

(B)Model 2
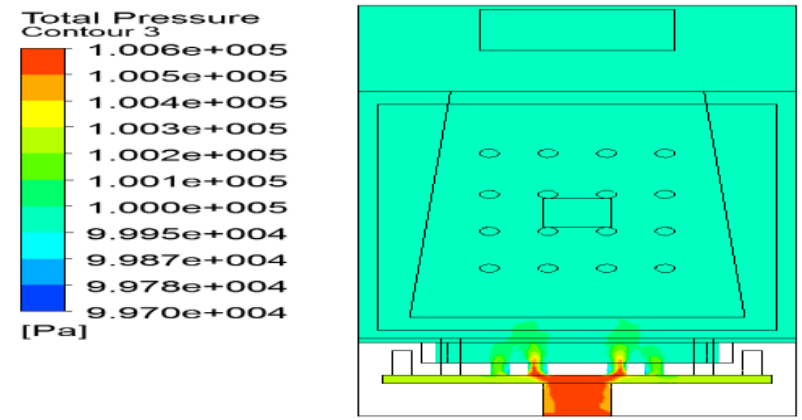

(B)Model 2

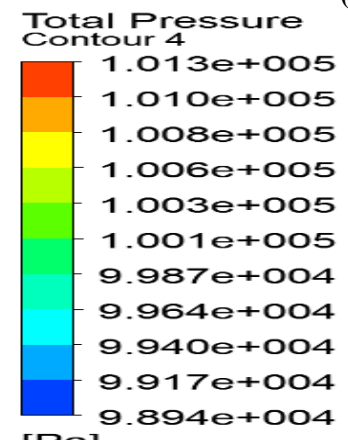

[Pa]

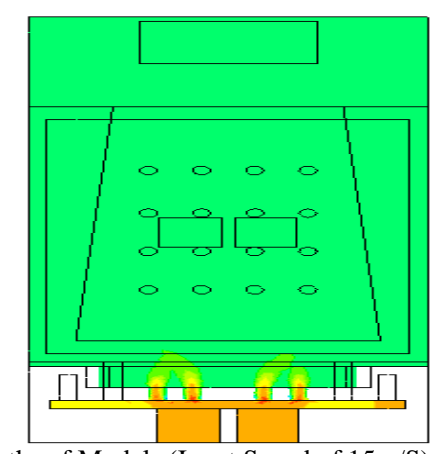

Fig.: 8.Pressure Levels in Air Paths of Models (Input Speed of $15 \mathrm{~m} / \mathrm{S}$ ).

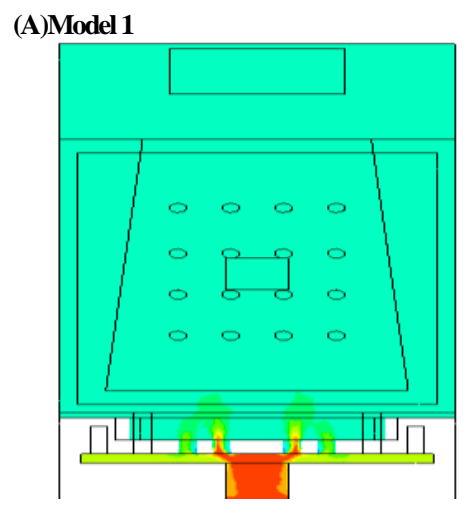

(B)Model 2

Total Pressure
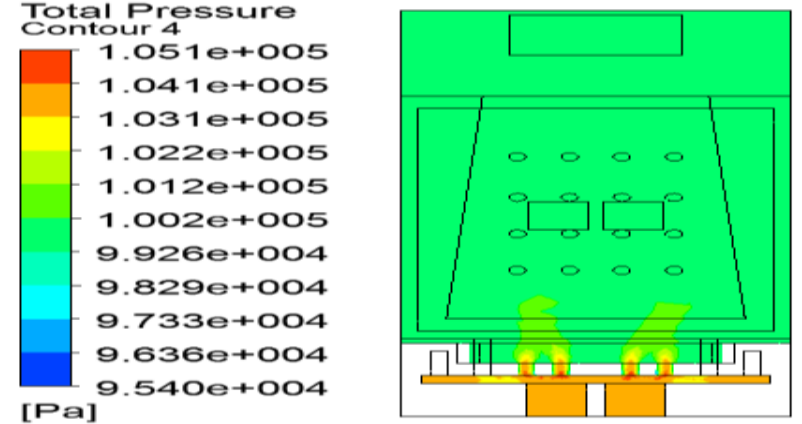

Fig. 9:.Pressure Levels in Air Paths of Models (Input Speed of 30m/S).

Fig. 8 and Fig. 9 show the pressure levels in air patch at different wind speeds, and Fig. 8 applied a speed of $15 \mathrm{~m} / \mathrm{s}$ to the air inlet. Here, model 1 showed the maximum pressure of $100.60 \mathrm{kPa}$. Model [2] also got a pressure of $101.30 \mathrm{kPa}$. Fig. 9 shows the resulting values with the inlet set at $30 \mathrm{~m} / \mathrm{s}$, and model 1 showed a pressure of $102.20 \mathrm{kPa}$ while model 2 showed a pressure of $105.10 \mathrm{kPa}$. We saw that both resulting values showed the greatest pressure at the junction of air blower and air path.

\section{Conclusion}

We have studied the flow as affected by the shape and wind speed of ventilated seats and have come up with the following conclusion.

1) In studying the flow in the ventilated seats as affected by different shapes and wind speeds, we examined the overall flow speeds in the models. With the wind speed at $15 \mathrm{~m} / \mathrm{s}$, model 1 got a speed of $29.91 \mathrm{~m} / \mathrm{s}$ and model 2 got a speed of $44.81 \mathrm{~m} / \mathrm{s}$. With the wind speed at $30 \mathrm{~m} / \mathrm{s}$, model 1 got a speed of $44.21 \mathrm{~m} / \mathrm{s}$ and model 2 got a speed of $88.60 \mathrm{~m} / \mathrm{s}$. The shape of model 2 is shown to have higher speeds.

2) We examined the speeds in air path as affected by the shape and wind speed of ventilated seats. We further saw that with the initial input speed at $30 \mathrm{~m} / \mathrm{s}$, model 1 got a speed of $60.25 \mathrm{~m} / \mathrm{s}$ and model 2 got a speed of $88.60 \mathrm{~m} / \mathrm{s}$. 
3) We checked the pressure in air path as affected by the shape and wind speed of ventilated seats. With the initial wind speed at $15 \mathrm{~m} / \mathrm{s}$, model 1 got the maximum pressure of $100.60 \mathrm{kPa}$. With the initial wind speed of $30 \mathrm{~m} / \mathrm{s}$, model 1 got the maximum pressure of $102.30 \mathrm{kPa}$ and model 2 got a pressure of $105.10 \mathrm{kPa}$.

4) We saw that the highest speed and greatest pressure in the ventilated seats were shown at the junction of air blower and air path.

5) From the above results, we have acquired data for designing ventilated vehicle seats and we expect that this will lead to the production of further improved ventilated seats.

\section{Acknowledgment}

This work was (partly) supported by Advanced Motor Parts Regional Innovation Center AMPRIC) of Kongju National University administered by MSS (Ministry of SMEs and Startups), Korea.

\section{References}

[1] Kuznetsov, A. V. (2002). Fluid flow and heat transfer analysis of Couette flow in a composite duct. ActaMechanica, 140 (3-4), 163 170.

[2] Zlatanovski, T. (1995). Solution of the laminar duct flow problem by a boundary integral equation method. Archive of Applied Mechanics, 65(5), 346-364

[3] Someswara Rao, S., PattabhiRamacharyulu, N. Ch. \& Krishnamurty, V. V. G. (1969). Laminar forced convection in elliptic ducts. Applied Scientific Research, 21(1), 185-193.

[4] Sert, I. O., Sezer-Uzol, N. \&Kakaç, S. (2013). Numerical analysis of transient laminar forced convection of nanofluids in circular ducts. Heat and Mass Transfer, 49(10), 1405-1417.

[5] Kano. H. M., Date, K. \& Oya, T. (1997). Flow Analysis in Nozzle Hole in Consideration of Cavitation.Society Automotive Engineering, $1219,97-108$

[6] Sung, N. W. \& Song, J. W. (1996). Flow Analysis of a Chamber Type Intake Manifold Engine. Society Automotive Engineering, 1197, 41-50.

[7] Jue, T. C. (2000). Analysis of heat and fluid flow in partially divided fluid saturated porous cavities. Heat and Mass Transfer, 36(4), 285-294.

[8] Zheng, H., Lei, Y. \& Song, P. (2017). Hydraulic retarders for heavy vehicles: Analysis of fluid mechanics and computational fluid dynamics on braking torque and temperature rise. International Journal of Automotive Technology, 18(3), 387-396

[9] Abbadeni, M., Zidane, I., Zahloul, H., Fatu, A. \&Hajjam. M. (2017). Finite element analysis of fluid-structure interaction in the hydromechanical deep drawing process. Journal of Mechanical Science and Technology, 31(11), 5485-5491.

[10] Sreejith, B., Jayaraj, K., Ganesan, N. El, A. (2014). Finite element analysis of fluid-structure interaction in pipeline systems $[\mathrm{J}] . \mathrm{Nu}-$ clear Engineering and Design, 227(3) 313-322. 